\title{
In situ scanning electron microscopy indentation studies on multilayer nitride films: Methodology and deformation mechanisms
}

\author{
K.A. Rzepiejewska-Malyska ${ }^{\text {a) }}$ \\ EMPA, Materials Science and Technology-Laboratory for Mechanics of Materials and \\ Nanostructures, Thun $\mathrm{CH}-3602$, Switzerland \\ W.M. Mook \\ EMPA, Materials Science and Technology—Laboratory for Mechanics of Materials and \\ Nanostructures, Thun, BE Switzerland \\ M. Parlinksa-Wojtan \\ EMPA, Materials Science and Technology—Nanoscale Materials Science, Dübendorf, ZH Switzerland \\ J. Hejduk \\ Polish Academy of Sciences-Institute of Electron Technology, Warsaw 02-668, Poland
}

J. Michler

EMPA, Materials Science and Technology—Laboratory for Mechanics of Materials and Nanostructures, Thun, BE Switzerland

(Received 31 July 2008; accepted 5 December 2008)

Systematic studies of the deformation mechanisms of multilayer transition metal nitride coatings TiN/CrN, TiN/NbN, and $\mathrm{NbN} / \mathrm{CrN}$, and corresponding reference coatings of $\mathrm{TiN}, \mathrm{NbN}$, and $\mathrm{CrN}$ deposited by a direct current (dc) magnetron sputtering process onto silicon $\langle 100\rangle$ have been performed. Mechanical characterization was conducted using a combination of microindentation and nanoindentation in the load range 30 to $150 \mathrm{mN}$ and 0.5 to $3.5 \mathrm{mN}$, respectively. For both load ranges, scanning electron microscopy (SEM) in situ indentation was used to observe the indentation process including any pileup, sink-in, and fracture mechanisms specific to each coating. The coatings' microstructure, both before and after indentation, was analyzed using transmission electron microscopy (TEM). It was possible to both correlate the indentation load-displacement response to surface roughness effects and fracture modes (substrate and film cracking) and observe deformation mechanisms within the coatings.

\section{INTRODUCTION}

Transition metal nitride coatings have traditionally been used as protective coatings for different types of cutting tools and microelectronics and as diffusion barriers for the semiconductor industry, and they are now being considered for use as protective coatings in microelectromechanical systems (MEMS). ${ }^{1,2}$ This is due to their high hardness and reasonable toughness, which combine to give superior tribological performance compared to uncoated devices. ${ }^{3-5}$ Tribological issues are especially important for MEMS applications where excessive wear of the single- and polycrystalline silicon elements in motion drastically limit device designs and lifetimes.

The most extensively explored transition metal nitride coatings are TiN, CrN, NbN, TaN, VN, and ZrN. ${ }^{1,2,6}$ This work focuses on three of these, namely $\mathrm{TiN}, \mathrm{CrN}$, and $\mathrm{NbN}$, because of their outstanding mechanical properties.

\footnotetext{
a) Address all correspondence to this author. e-mail: Karolina.Rzepiejewska@empa.ch DOI: $10.1557 /$ JMR.2009.0139
}

All of these transition metal nitrides are relatively hard with values ranging from 21 to $25 \mathrm{GPa}$ for $\mathrm{TiN}^{7-9}$ from 14 to $22 \mathrm{GPa}$ for $\mathrm{CrN}^{10,11}$ and from 6 to $45 \mathrm{GPa}$ for $\mathrm{NbN},{ }^{12-14}$ depending on the deposition technique and its conditions. Moreover, all of these materials are reported to have good wear resistance ${ }^{6,14,15}$ and fracture toughness. 1,16

These materials also possess some individual properties that differentiate them from each other. Both $\mathrm{CrN}$ and $\mathrm{NbN}$ have good oxidation and corrosion resistance, ${ }^{17,18}$ contrary to TiN. On the other hand, TiN is biocompatible, ${ }^{19,20}$ can act as a good diffusion barrier, ${ }^{21,22}$ and exhibits interesting optical properties. ${ }^{18}$ $\mathrm{NbN}$ and TiN both have high melting points, ${ }^{14}$ and NbN shows high electrical conductivity. ${ }^{23,24}$ Thus, NbN was first developed for a variety of applications such as superconducting electronics, ${ }^{25}$ field-emission cathodes ${ }^{26}$ and microelectronics. Such interesting combinations of properties have brought these nitrides under continuous development since mid-1980s, ${ }^{18,25}$ not only for tribological applications ${ }^{3,27}$ but also for decorative 
applications in the case of TiN. ${ }^{28}$ It is thought that if these constituent materials could be properly combined, for example as multilayer nanolaminates, their combined properties could be tailored for specific applications.

Multilayer coatings are reported to have enhanced resistance to wear, cracking, and fracture when compared with single-layered structures. ${ }^{8,29}$ This is true for both epitaxial superlattice structures ${ }^{8}$ and polycrystalline multilayer thin films ${ }^{30}$; however, enhancement mechanisms for these two laminate structures differ because of microstructural differences. The hardness increase of single-crystal nanolaminates is generally attributed to the superlattice effect ${ }^{31,32}$ while a rule-of-mixture argument is used for polycrystalline coatings. ${ }^{29,30,33}$ Any increase beyond the rule-of-mixture value for polycrystalline nanolaminates is often explained by the modified Hall-Petch theory. ${ }^{34,35}$ The improved fracture toughness of the multilayer coatings compared with the singlelayer coatings can be explained by crack deflection at the interlayer interfaces. ${ }^{36}$ Moreover, any dislocation multiplication in adjacent layers is hampered by the layer interfaces that can act as grain boundaries. ${ }^{37}$

A full understanding of the deformation and fracture mechanisms of multilayer coatings has been hindered by their complexity. ${ }^{38}$ Depending on the constituent materials in the multilayer coating, polycrystalline nanolaminate structures are reported to deform by different mechanisms. The most commonly observed are grain-boundary sliding for $\mathrm{TiN} / \mathrm{NbN}$ and $\mathrm{TiN} /(\mathrm{Ti}, \mathrm{Al}) \mathrm{N}^{31,39}$ and densification underneath the indentation imprint for TiN/NbN. ${ }^{40,41}$

Hard materials, such as transition metal nitrides and their multilayer combinations, are generally characterized by their hardness, $H$, reduced modulus, $E_{\mathrm{r}}$, and elastic recovery, $W_{\mathrm{e}}$. These quantities can be determined from load-displacement curves obtained by instrumented indentation. ${ }^{42}$ However, a number of assumptions concerning the material behavior must be made when analyzing indentation data. Most models are based on the indentation of a flat, elastic half-space and the assumption that the tip area function (calculated by indenting a reference material) is applicable to other, similar materials. Mechanical properties such as nanohardness and reduced modulus have been widely studied for a number of different nitride multilayer systems. The most extensively tested among others are TiN/CrN ${ }^{11,32}$ and $\mathrm{TiN} / \mathrm{NbN}^{41,43}$ and more complex combinations containing $\mathrm{CrN}$ such as TiN-CrAlN and $\mathrm{CrN}-\mathrm{CrAlN}$. $^{44,45}$

However as shown in Sec. III. D, even the same class of materials (in this case metal nitrides) can behave differently at both the micro- and nanoscales with regard to material pileup and sink-in around the tip during an indentation. These types of behaviors can greatly affect both the calculated hardness and modulus values and are not apparent by observing only the load-displacement response. On the other hand, thin-film fracture is generally seen in instrumented indentation as a pop-in. ${ }^{46}$ However, this may also be misleading as it is shown in Sec. III. D. 1 that crack initiation is not always associated with pop-in events.

These issues can be addressed by in situ indentation performed inside a scanning electron microscope (SEM) since this technique allows for the pileup, sink-in crack initiation and propagation and shear band formation ${ }^{47}$ to be observed at the scale of interest in real time. This provides additional information on fracture toughness and strain hardening behavior that facilitates proper quantitative data evaluation, enabling a more accurate calculation of contact area and an improved mechanical model. ${ }^{48}$ This information, when combined with postmortem transmission electron microscopy (TEM) studies of the film cross sections beneath the indents, increases understanding of the underlying deformation mechanisms of the studied coatings.

Our previous work was focused on in situ SEM microindentation studies of $\mathrm{TiN}, \mathrm{CrN}$, and their multilayer combinations. ${ }^{49}$ In this paper, three multilayer coatings, namely $\mathrm{TiN} / \mathrm{CrN}, \mathrm{NbN} / \mathrm{CrN}$, and $\mathrm{TiN} / \mathrm{NbN}$, with individual layer thickness of approximately $17 \mathrm{~nm}$, consisting of 20 periods in total, were systematically investigated by both in situ SEM micro- and nanoindentation. For comparison, single-layer reference coatings of $\mathrm{TiN}, \mathrm{CrN}$, and $\mathrm{NbN}$ were deposited at least as thick as their multilayer counterparts. In situ SEM microindentation was used to investigate the presence of pileup and sink-in, as well as cracking behavior at the microscale for all of the deposited film/ substrate combinations. This large-scale indentation was complemented by in situ high-resolution SEM nanoindentation, which provided information about nanomechanical behavior for depths not exceeding the $15 \%$ of the total coating thickness. Cross sections of the residual indent impressions were created by focused ion beam (FIB) milling and analyzed using TEM so that the type of microstructure, as well as deformation mechanisms within the films, could be characterized. The average chemical composition of the thick reference coatings was assessed with glow discharge optical emission spectroscopy (GDOES).

\section{EXPERIMENTAL DETAILS}

Transition nitride multilayer thin films were deposited with ultrahigh vacuum (UHV) direct current (dc) magnetron sputtering in a Leybold L400Sp system on $\langle 100\rangle$ oriented silicon substrates at a substrate temperature of $\sim 70{ }^{\circ} \mathrm{C} .{ }^{50,51}$ Three different types of multilayer combinations, namely $\mathrm{TiN} / \mathrm{NbN}, \mathrm{NbN} / \mathrm{CrN}$, and $\mathrm{TiN} / \mathrm{CrN}^{49}$ and corresponding single-layer reference coatings of TiN, NbN, and CrN were deposited (see Table I). ${ }^{45,49}$

Hardness and Young's modulus values of the coatings were obtained by nanoindentation using a TriboIndenter (Hysitron, Inc., Minneapolis, MN) equipped with a Berkovich-shape diamond tip. This indenter tip geometry 
TABLE I. Basic information about investigated films.

\begin{tabular}{|c|c|c|c|c|c|c|c|}
\hline \multirow[b]{2}{*}{ Type of coating } & \multirow[b]{2}{*}{ Materials } & \multirow{2}{*}{$\begin{array}{l}\text { Range of column } \\
\text { width (nm) }\end{array}$} & \multicolumn{2}{|c|}{$\begin{array}{l}\text { Average composition } \\
\text { (at. } \%)\end{array}$} & \multirow{2}{*}{$\begin{array}{l}\text { Average thicknesses of the } \\
\text { layers in the coating }(\mathrm{nm})\end{array}$} & \multirow{2}{*}{$\begin{array}{l}\text { Measured thickness } \\
\text { of the coating (nm) }\end{array}$} & \multirow[b]{2}{*}{ Compression (\%) } \\
\hline & & & $X$ & $\mathrm{~N}$ & & & \\
\hline \multirow[t]{3}{*}{ Reference } & TiN & $\sim 10-30$ & 35 & 65 & $\ldots$ & 646 & $\sim 4$ \\
\hline & $\mathrm{CrN}$ & $\sim 150$ & 85 & 15 & $\ldots$ & 1069 & $\sim 11$ \\
\hline & $\mathrm{NbN}$ & $\sim 15$ & 55 & 45 & $\ldots$ & 780 & $\sim 3.8$ \\
\hline \multirow[t]{3}{*}{ Multilayers } & $\mathrm{TiN} / \mathrm{NbN}$ & $\sim 30-60$ & $\ldots$ & $\ldots$ & $16.66 / 16.28$ & 659 & $\sim 19.5$ \\
\hline & $\mathrm{TiN} / \mathrm{CrN}$ & $\sim 50$ & $\ldots$ & $\ldots$ & $18.03 / 17.52$ & 697 & $\sim 20.4$ \\
\hline & $\mathrm{NbN} / \mathrm{CrN}$ & $\sim 15-200$ & $\ldots$ & $\ldots$ & $19.61 / 18.65$ & 765 & $\sim 16.5$ \\
\hline
\end{tabular}

Column widths and thicknesses were determined by TEM, composition was measured with GDOES, and the compression (\%) is the decrease in film thickness below $30 \mathrm{mN}$ indents. $(X=\mathrm{Ti}, \mathrm{Cr}, \mathrm{Nb})$.

allows for indentation while applying relatively low strain gradients, which decreases the probability of sample cracking. The penetration depth was limited to the range of 5 to $15 \%$ of the total coating thickness to minimize errors associated with surface effects (the lower limit) and the influence of the substrate (the upper limit). ${ }^{52}$ The coating surface influence can have its source in many different principles. Too low of an indentation depth may result in unnaturally high hardness caused by unfavorable ratios of surfaces roughness to tip radius of curvature and surface roughness to indentation depth. ${ }^{53}$ To stay within the optimal displacement regime, the applied load ranged from 0.5 to $3.5 \mathrm{mN}$. The indenter was operated in the open-loop loading mode with loading and unloading portions of $5 \mathrm{~s}$ each. Therefore, the average load rate varied depending on the maximum load, namely $0.1 \mathrm{mN} / \mathrm{s}$ for $0.5 \mathrm{mN}, 0.2 \mathrm{mN} / \mathrm{s}$ for $1 \mathrm{mN}, 0.5$ $\mathrm{mN} / \mathrm{s}$ for $2.5 \mathrm{mN}$, and $0.7 \mathrm{mN} / \mathrm{s}$ for $3.5 \mathrm{mN}$. These loading rates did not influence the measured hardness or reduced modulus. To ensure accurate data estimation, values presented in this work are averages of at least eight measurements, while the error bars represent three standard deviations that correspond to the range containing $99.97 \%$ of possible values. ${ }^{54}$

To investigate the incipient stages of deformation at displacements of less than $15 \%$ of the coating thickness, a Hysitron PicoIndenter (Hysitron, Inc.) integrated into high-resolution SEM (Hitachi S-4800, Japan) was used. ${ }^{55}$

Indentation experiments were also performed at the microscale with the in situ microindenter developed and integrated into a Zeiss DSM962 SEM (Germany) by Rabe et al. ${ }^{48}$ For these experiments, a cube corner indenter tip was used. The load-controlled indentation experiment with a maximum load of $150 \mathrm{mN}$ was performed on all investigated samples. The indentation experiment consists of $60 \mathrm{~s}$ of linear loading, a hold segment at maximum load, and unloading segment, $30 \mathrm{~s}$ long each. Therefore, the average loading and unloading rate were equal to 2.5 and $5 \mathrm{mN} / \mathrm{s}$, respectively. Such a high load was necessary to reach the onset of crack formation and failure modes characteristic for each type of coating. As the depth of indentation far exceeded $15 \%$ of the coating thickness for these experiments, the mechanical behavior of the coating-substrate system was probed.

TEM foils were prepared in a way that the coatings' microstructure and deformation mechanisms could be characterized. Foils of the cross sections of the as-deposited coatings and of the residual plastic impressions from $30 \mathrm{mN}$ indents were prepared using a FIB-Dual Beam FEI STRATA DB235 external lift-out technique (FEI, The Netherlands). Transmission electron microscopy in both bright field (BF) and dark field (DF) were performed on a CM30 Philips LaB6 TEM (FEI) using $300 \mathrm{kV}$ acceleration voltage, reaching a point resolution of $2.6 \AA$.

\section{RESULTS AND DISCUSSION}

\section{A. Microstructure of the investigated thin films}

Dark-field micrograph analysis allowed for comparison of the microstructure for all coatings. As can be seen for both reference and multilayer coatings, the structure is generally nanocrystalline with randomly oriented grains as seen in Fig. 1. Reference coatings show columnar growth with increasing grain size toward the film surface. The average column width varies between $15 \mathrm{~nm}$ for $\mathrm{NbN}$ and $150 \mathrm{~nm}$ for $\mathrm{CrN},{ }^{56}$ as summarized in Table I. Both $\mathrm{CrN}$ and TiN have columns extending through the entire film thickness, but TiN shows highangle boundaries whereas $\mathrm{CrN}$ has low-angle boundaries columns. $\mathrm{NbN}$ grains exhibit a subgranular structure with many differently oriented zones. A nucleation zone with an unresolved nature (amorphous or nanocrystalline) was observed close to the substrate/film interface.

From the TEM micrographs in Fig. 1, the constituent layers in the multilayer coatings interacted differently in each pair during deposition. The $\mathrm{NbN} / \mathrm{CrN}$ multilayers show smooth layers with sharp and smooth interfaces in the BF image. However, columnar grains grow within multilayered structure having a sublayer structure. In the $\mathrm{DF}$ image, the $\mathrm{CrN}-\mathrm{NbN}$ interface in the direction of deposition is very sharp, contrasting with the $\mathrm{NbN}-\mathrm{CrN}$ interface. This may occur because the $\mathrm{NbN}$ has highangle boundaries unlike $\mathrm{CrN}$, which has low-angle boundaries. The TiN/CrN is characterized by flat layers 


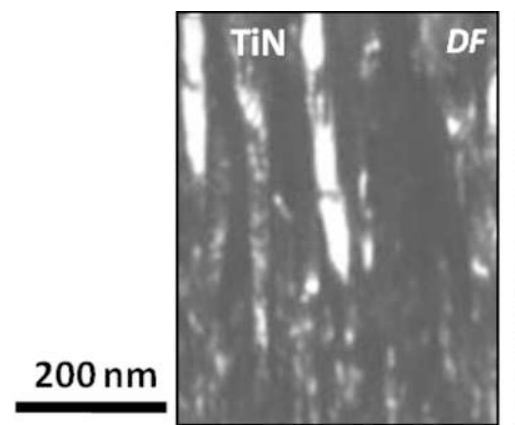

(a)

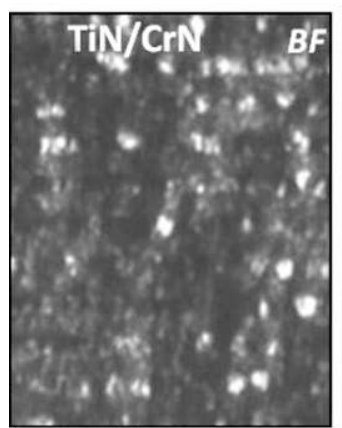

(d)

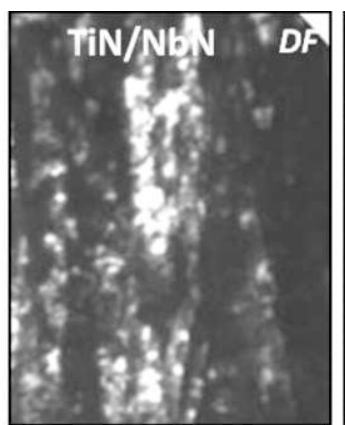

(b)

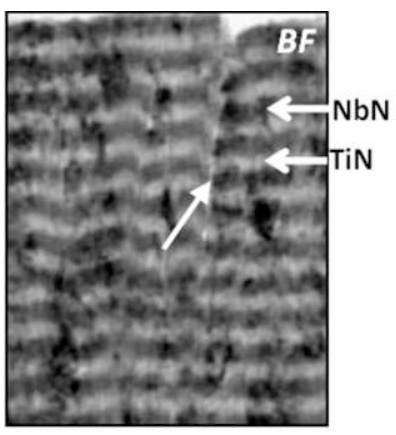

(c)

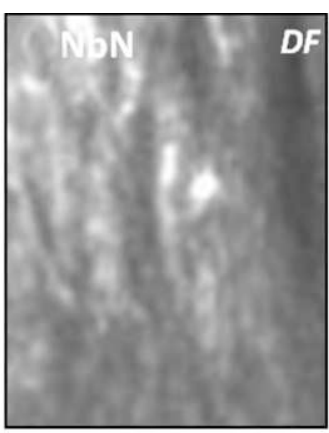

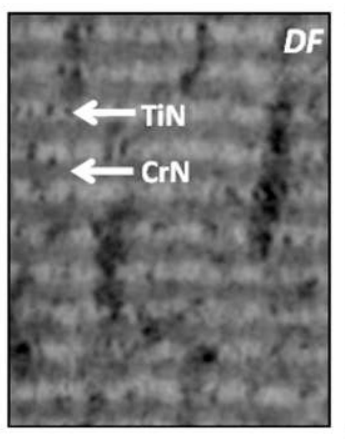

(e)

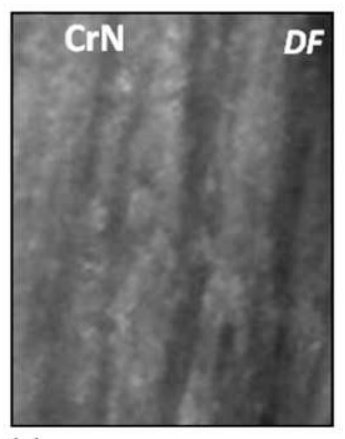

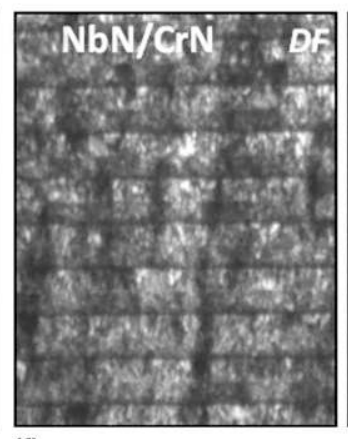

(f)

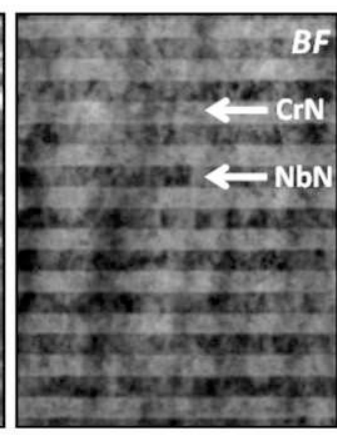

FIG. 1. TEM cross-sectional analysis for as-deposited coatings with dark field (DF) for all coatings in addition to bright field (BF) for multilayers. (a) TiN showing high levels of misorientation. (b) TiN/NbN showing columnar grain growth through layers. (c) $\mathrm{NbN}$ exhibiting granular structure with subgranular misorientation. (d) TiN/CrN showing multilayer grain orientation. (e) CrN showing large columnar grains. (f) $\mathrm{NbN} / \mathrm{CrN}$ with crisp interfaces.

and interfaces of higher roughness compared with $\mathrm{NbN} /$ $\mathrm{CrN}$. This combination ${ }^{49}$ exhibits a granular microstructure such that the columns can grow through several layers. ${ }^{30} \mathrm{TiN} / \mathrm{NbN}$ has nonflat layers with rough and wavy interfaces, which is probably caused by the competitive growth of strongly misoriented columnar grains. For the $\mathrm{TiN} / \mathrm{NbN}$ combination, the grain boundaries are visible as white vertical lines [see Fig. 1(b), arrow]. Voids occurred as a result of kinetic limitations of the deposition process that separate the columnar grains. In the TiN constituent layers for both $\mathrm{TiN} / \mathrm{NbN}$ and $\mathrm{TiN} /$ $\mathrm{CrN}$ combinations, small grains of TiN are nested between larger columnar grains, and therefore the presence of the layered structure confines the TiN microstructure.

\section{B. Chemical composition of reference coatings}

The chemical composition of the reference coatings was assessed using the GDOES technique. The use of thick coatings allows for more accurate data interpretation. The as-deposited materials are nonstoichiometric to varying degrees as is summarized in Table I. Following that, the TiN composition is very rich in $\mathrm{N}(\sim 65$ at. $\%)$, while $\mathrm{CrN}$ contains only $15 \% \mathrm{~N}$ (see Table I). ${ }^{16}$ The $\mathrm{NbN}$ is close to stoichiometric composition, which is in agreement with previous studies. ${ }^{57}$ The concentration of each constituent element is constant through the film thickness. Relatively low deposition temperatures (substrate temperature during deposition $\sim 70{ }^{\circ} \mathrm{C}$ ) implies that the deposition is not thermodynamically stable and suggests that the coatings contain a mixture of different phases. ${ }^{58}$ Chemical composition was studied extensively for each of the binary combinations and is reported for Ti-N, ${ }^{58-60}$ for $\mathrm{Nb}-\mathrm{N},{ }^{61,62}$ and for $\mathrm{Cr}-\mathrm{N} .{ }^{63,64}$

\section{Ex-situ nanoindentation}

Film systems were indented with a Hysitron TriboIndenter with loads ranging from 0.5 to $3.5 \mathrm{mN}$ to quantify hardness and reduced modulus without substrate influence. These results can be seen in Fig. 2. The $\mathrm{NbN}$ reference coating shows much higher hardness and reduced modulus when compared with the other coatings. Hardness increases in this case with increasing indentation depth, from 20.4 to $32.7 \mathrm{GPa}$, while reduced modulus maintains a value between 276 and $287 \mathrm{GPa}$ throughout the range of applied loads. All of the other reference and multilayer films had hardnesses in the range of 10 to $20 \mathrm{GPa}$, while reduced moduli ranged from 180 to $240 \mathrm{GPa}$. Within the measurement accuracy, the two nanolaminates that contain the $\mathrm{NbN}$ do not follow the rule of mixture either for hardness or for modulus. The values decrease to the other constituent material properties; the reason for which is explained in Sec. III. D. 2. As is shown with ex situ nanoindentation alone, it is impossible to determine why the hardness and 

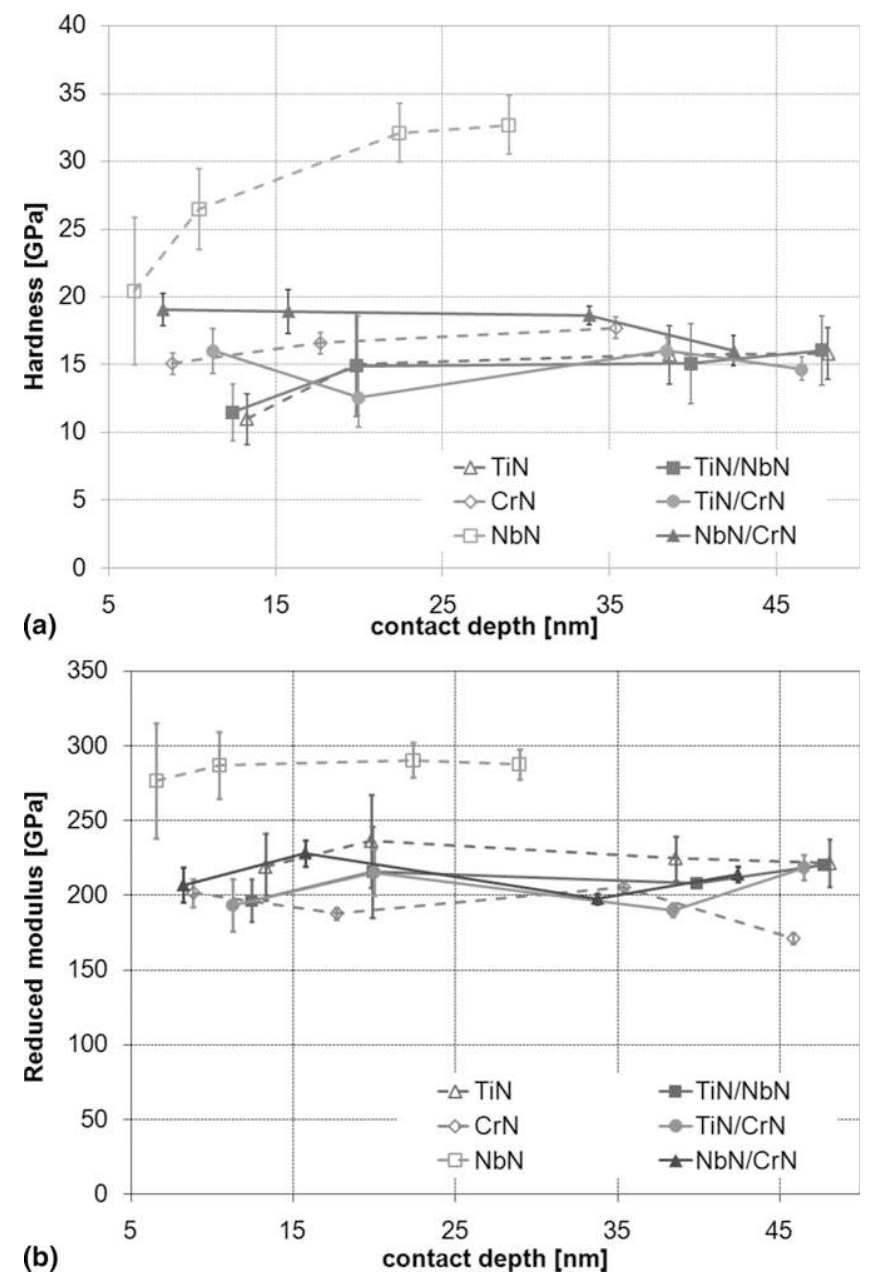

FIG. 2. Hardness (a) and reduced modulus (b) as a function of the contact depth for all coatings from ex situ nanoindentation determined using the Oliver and Pharr approach.

reduced modulus values are practically the same for all the coatings even though they are made from different materials. For further insight, the in situ SEM indentation at both the micro- and nanoscale was performed.

\section{In situ SEM micro/nanoindentation}

The main goal for the in situ investigation was to correlate any cracking and spalling that may be observed during indentation as seen in Figs. 3 and 6 with events that occurred on the corresponding load-displacement curves in Figs. 5 and 8 such as pop-ins or other discontinuities. The in situ indentation performed at the microscale allowed for fracture mechanism observations, while indentation at the nanoscale concentrated on pileup and sink-in of the films independently on the substrate influence.

\section{In situ SEM microindentation}

During in situ SEM microindentation, movies can be recorded throughout the indentation process. Indentations to a maximum load of $150 \mathrm{mN}$ were conducted, and the residual impressions from these indentations are compiled in Fig. 3. The load-displacement response from these are shown in Fig. 5, where an indentation into the bare $\mathrm{Si}$ is repeated in each figure as an aid when comparing coating performance. Figures 5(a)-5(c) show multilayers and corresponding reference coatings responses. Figure 5(d) shows the load-displacement curves for reference coatings for comparison. All films show cracking in Fig. 3 except for the $\mathrm{NbN}$ reference film, which spalled off during the first part of unloading [the inset of Fig. 3(c') shows the film at maximum load without cracking]. In this case, the spalling could be caused by either weak coating-substrate adhesion or high residual stress that can be superimposed on the contact stress. The spalled coating reveals the damage that occurred in the substrate in the form of lateral cracking, but it does not show up in the load-displacement curve in the form of a discontinuity [Fig. 5(d)]. For all of the other coatings, the initiation and growth of the radial cracks can be correlated to the load-displacement response by isolating individual in situ movie frames. For example, the initiation and growth of cracks in the $\mathrm{CrN}$ reference film can be seen in Fig. 4 where it is immediately apparent that there is not an excursion (in load or displacement) that corresponds to the visible cracking. This is true for the other specimens as well where the indentation depth and load for crack initiation along with the crack length at maximum load are compiled in Table II. These cracks are nucleated in the coatings during the loading portion of the indentation experiment and grow slowly and continuously until the maximum load is reached. Subsequently, they open more or even grow in during the unloading part of the test. Finally, they close again as the tip loses contact with the surface. The exact moment of the tip-material relative motion is visible on the load-displacement curves by a regular kink during unloading, marked out by the circle on Fig. 5(b).

In these films, the process of cracking is not rapid and does not provide quick energy release. The radial cracks within the coating are most likely the consequence of lateral cracking beneath the coating within the substrate similar to what is observed in Fig. 3(c). The repeating pop-ins present at $\sim 30 \mathrm{mN}$ further suggest that internal, nonvisible cracks occurred in this structure before appearing on the coating surface [Fig. 5(b), circle]. Substrate cracking enhances the local tensile strain within the coating, which contributes to the cracking. A pop-in was observed on the load-displacement curve only for $\mathrm{TiN} / \mathrm{NbN}$, albeit at a lower load than the surface crack was nucleated [Fig. 5(b), arrow]. Although these coatings happen to crack at high loads, they provide a significant improvement over the response of the bare $\mathrm{Si}$ substrate, which revealed many well-pronounced 


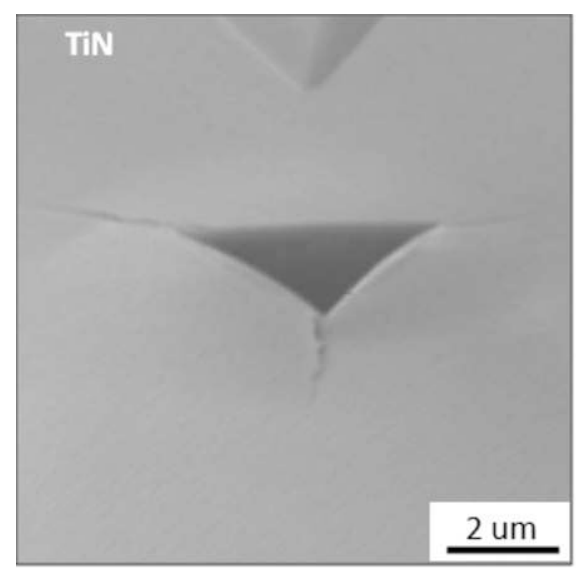

(a)

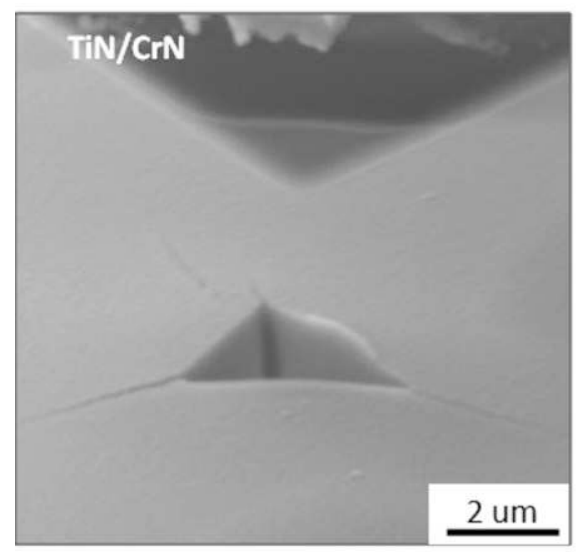

(d)

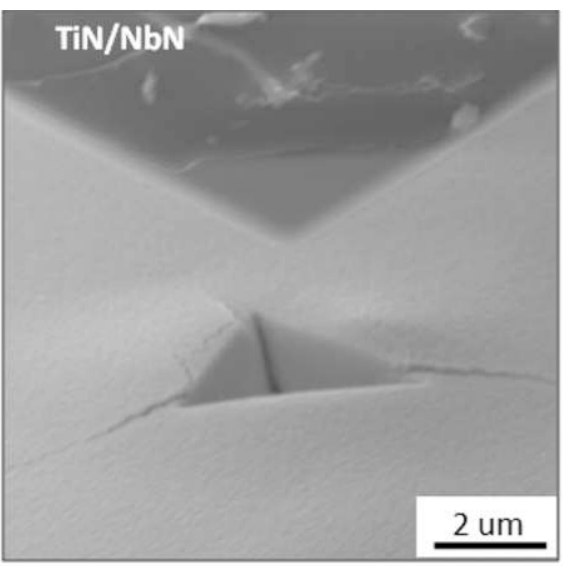

(b)

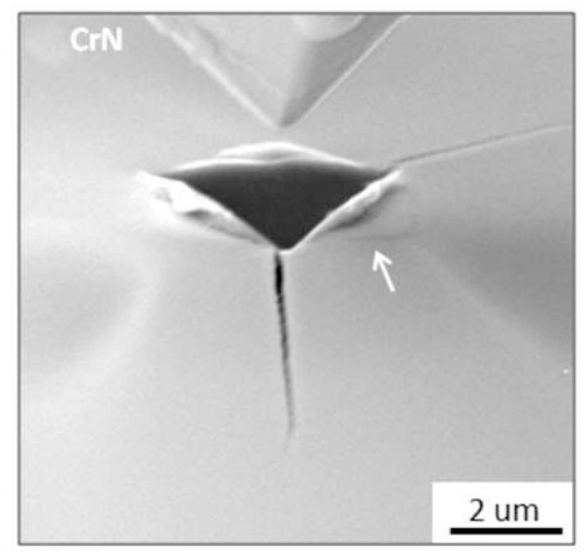

(e)

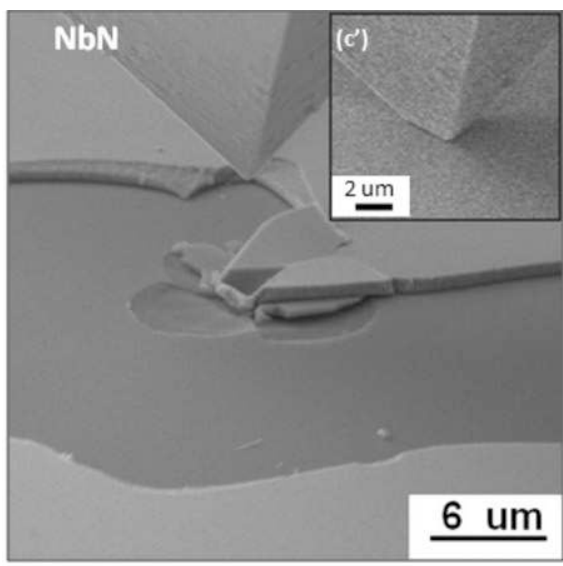

(c)

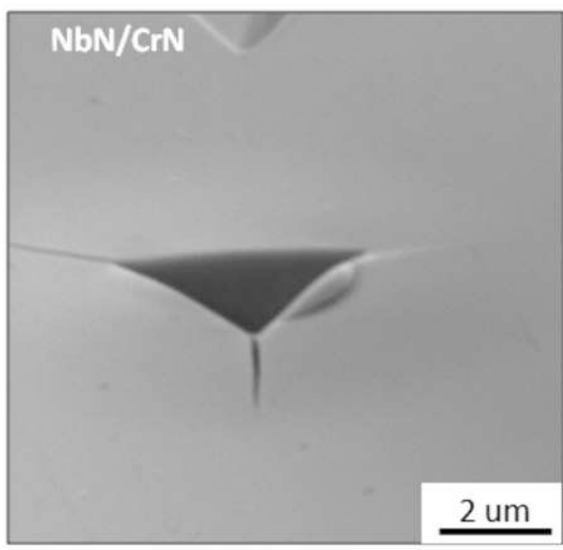

(f)

(b) TiN/NbN, (c) remnants of NbN coating, ( $c^{\prime}$ ) complete NbN coating under maximum load, (d) TiN/CrN, (e) $\mathrm{CrN}$, and (f) $\mathrm{NbN} / \mathrm{CrN}$.

pop-ins that did not happen for the coated substrates as seen in Fig. 5.

\section{In situ SEM nanoindentation}

In situ high-resolution SEM nanoindentation was performed using a Hysitron PicoIndenter. ${ }^{55}$ Applying a maximum load of $\sim 900 \mu \mathrm{N}$, which is close to the limit for this type of sensor, the deformation mechanisms of the coatings were studied independently from the influence of the substrate. Residual impressions from these indents can be seen in Fig. 6, while the corresponding load-displacement curves can be seen in Fig. 8. Roughnesses of these coatings vary and influence the initial stiffness during the indentation. This is clearly seen for $\mathrm{NbN} / \mathrm{CrN}$ in Fig. 8 where the load increases at once, unlike the TiN/NbN coating.

The deformation modes observed in situ during nanoindentation are consistent with the information available from the load-displacement curves. Indentation curves for $\mathrm{CrN}$ show significant plasticity, while $\mathrm{NbN}$ has greater elastic deformation [Fig. 8(d)]. The presence of TiN in the TiN/NbN multilayer coating determined the amount of the plasticity present during deformation [Fig. 8(b)].
Hardness values from the in situ SEM nanoindentation experiment were calculated using the contact area at maximum load determined from the in situ movies along the maximum load from the data in Fig. 8. These values, listed in Table III, depend on the SEM image resolution and are therefore subject to a small amount of error. They are compared with hardness values obtained using the Oliver and Pharr ${ }^{65}$ method from $1000 \mu \mathrm{N}$ indents obtained with a Hysitron TriboIndenter instrument. All of the coatings that contain $\mathrm{NbN}$ indicate that in situ SEM hardness values are higher than those obtained by the Oliver and Pharr method. For these coatings, a large amount of sink-in are visible during the experiment (see e.g., Fig. 7). Such phenomena as pileup and sink-in were not taken into account in the ex situ experiments. Therefore, the apparent contact area was overestimated, thus lowering both the hardness and reduced modulus. When accounting for the sink-in from the in situ indentations, hardness of the $\mathrm{TiN} / \mathrm{NbN}$ multilayer increases to $19 \mathrm{GPa}$, while the $\mathrm{NbN} / \mathrm{CrN}$ increases to more than $37 \mathrm{GPa}$. That is a $100 \%$ increase in calculated hardness when compared with the ex situ values calculated using the Oliver and Pharr method. 


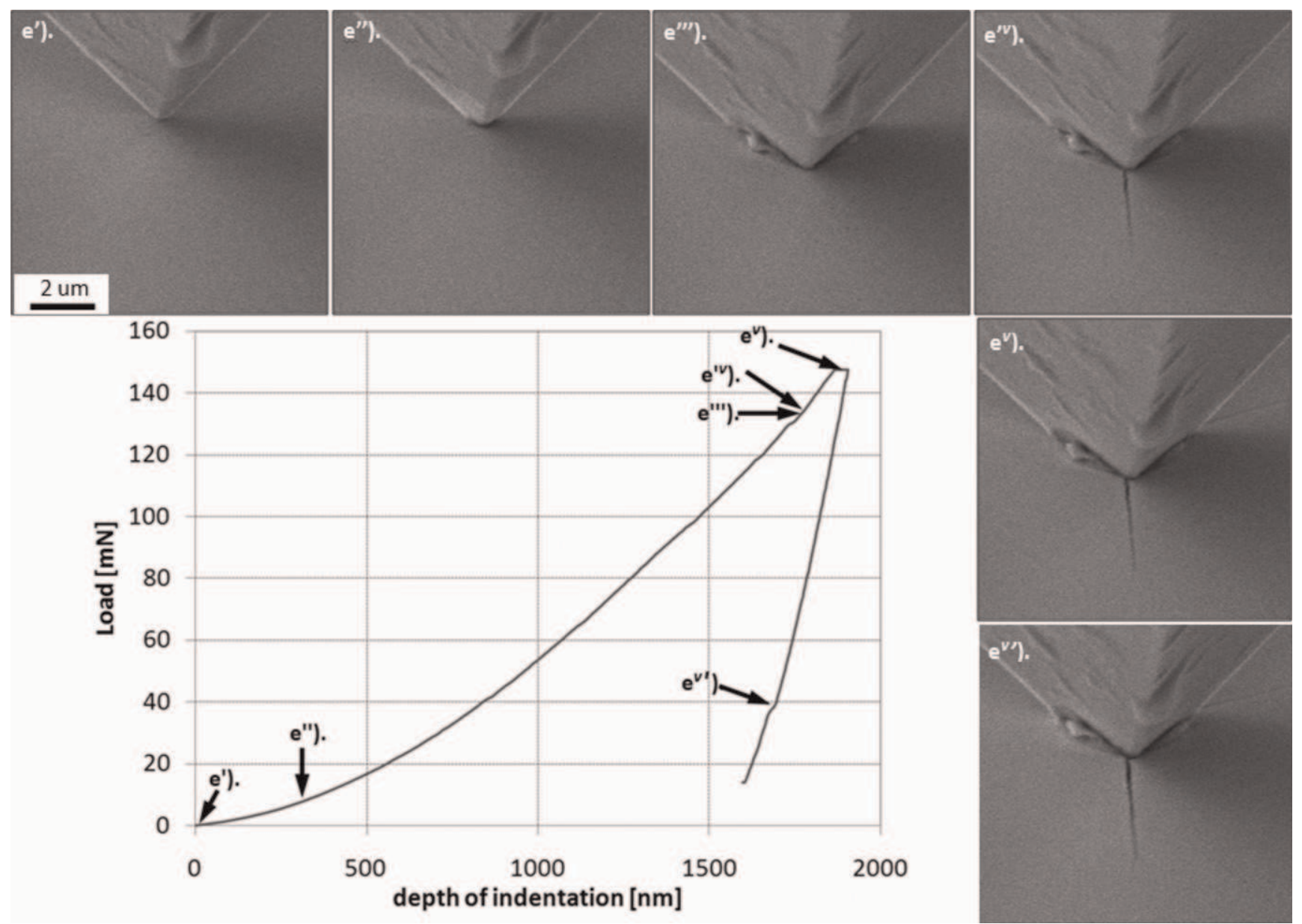

FIG. 4. Frames of indentation [see Fig. 3(e)] showing the different stages of deformation of the CrN reference coating and corresponding loaddisplacement curve. $\left(\mathrm{e}^{\prime}\right)$ First contact of the indenter tip with the coating surface area. ( $\left.\mathrm{e}^{\prime \prime}\right)$ First moment of pileup formation. ( $\left.\mathrm{e}^{\prime \prime \prime}\right)$ The moment of piling up of the coating just before the crack formation. $\left(\mathrm{e}^{\mathrm{v}}\right)$ First moment of cracking (crack appeared very rapidly). ( $\mathrm{e}^{\mathrm{v}}$ ) Coating under the maximum load. $\left(\mathrm{e}^{\mathrm{v} /}\right)$ The moment of tip form the coating reliving.

On the other hand, the materials that pile up demonstrate a decrease in the measured hardness (note that the contact between indenter tip and the $\mathrm{CrN}$ was obscured so an in situ hardness value could not be accurately determined for that case). For example, the TiN/CrN multilayer exhibits a decrease in calculated hardness from 14.9 to $10.5 \mathrm{GPa}$. Interestingly for the $\mathrm{NbN} / \mathrm{CrN}$ coating, where the reference films show dissimilar behaviors (sink-in for $\mathrm{NbN}$ and pileup for $\mathrm{CrN}$ ), sink-in is observed generating a hardness level equal to that of the $\mathrm{NbN}$ reference coating at the nanoscale.

\section{E. TEM analysis of the deformed area}

Cross-sectional TEM analysis of the plastic deformation beneath $30 \mathrm{mN}$ indents was conducted on both multilayers and reference coatings; the resulting images are shown in Fig. 9. From this, it can be seen that the TiN reference coating [Fig. 9(a)] deforms through cracks [Fig. $9\left(\mathrm{a}^{\prime}\right)$, arrow] and shears along the columnar boundaries, which result in formation of steps at the coating/substrate interface [Fig. $9\left(\mathrm{a}^{\prime \prime}\right)$ ]. This was also found in previous studies. ${ }^{38,49}$ Additionally, deformation and delamination in the form of buckling, characteristic for hard coatings on a softer substrate ${ }^{66}$ appeared at the coating/substrate interface. The $\mathrm{CrN}$ reference film [Fig. 9(e)] densifies, which is also consistent with previous studies. ${ }^{66}$ However, $\mathrm{CrN}$ was also subject to material flow, which occurred in the form of pileups along the indentation imprint edges and formation of shear bands visible in Fig. 3(e). The last among the reference coatings, $\mathrm{NbN}$ [Fig. 9(c)] behaves like an elastic plate, and the majority of the plastic deformation is confined within the substrate. The smallest amount of permanent deformation is observed for $\mathrm{NbN}$ and $\mathrm{TiN}$ reference coatings, $3.8 \%$ and $4 \%$, respectively, while for $\mathrm{CrN}$ it is $\sim 11 \%$ (see Table I). These values are the percent decrease in coating thickness underneath the indent. This deformation is a combination of changes in material volume caused by material porosity that may 


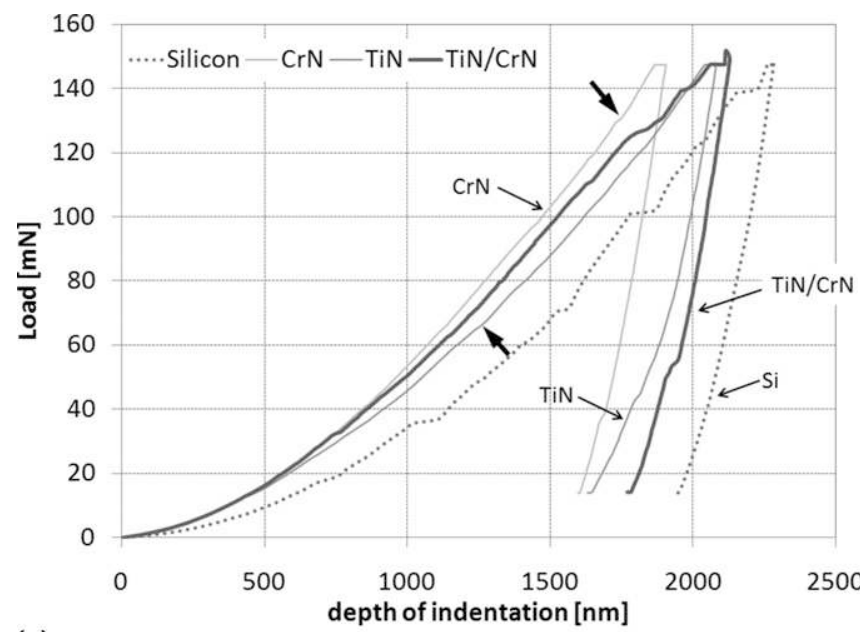

(a)

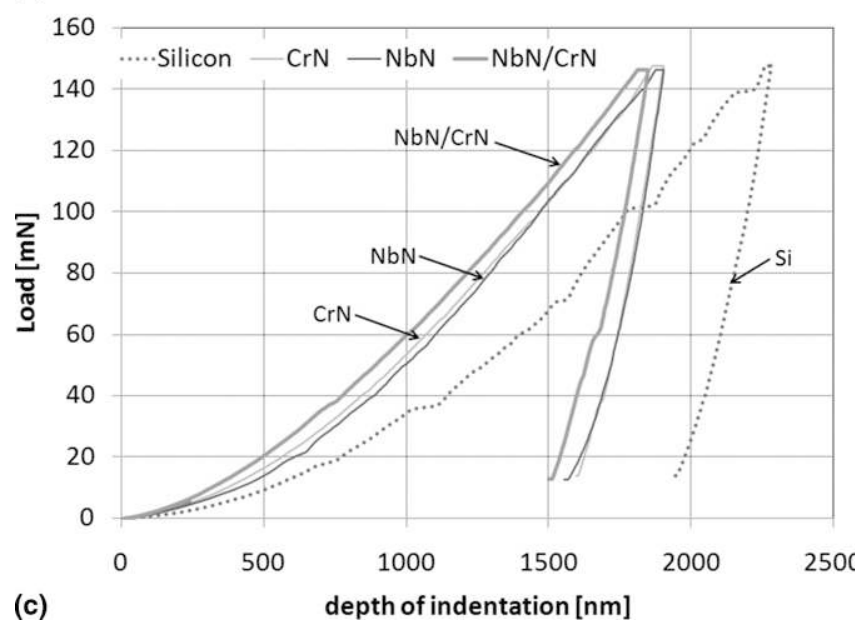

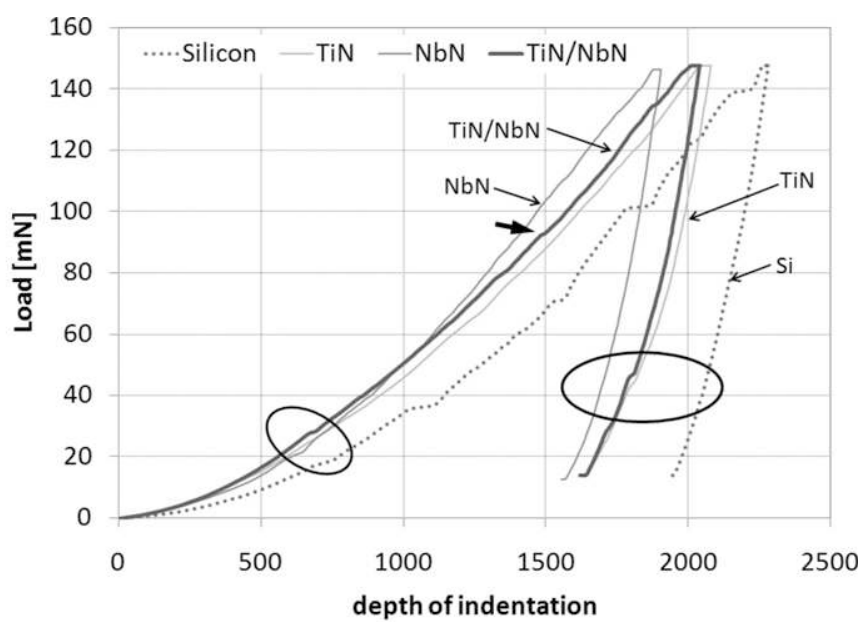

(b)

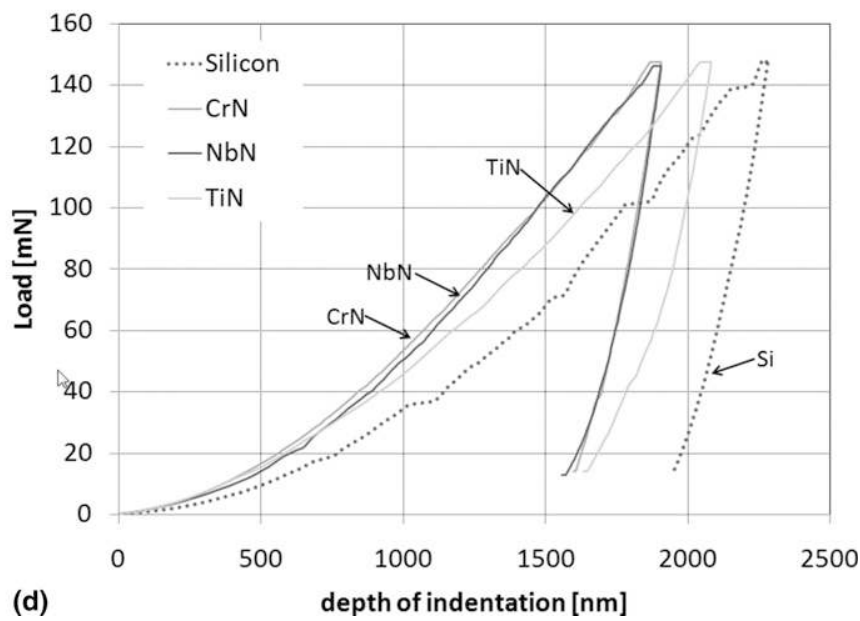

FIG. 5. Load-displacement curves of the multilayers and corresponding reference coatings that were recorded during in situ SEM microindentation (see Fig. 3). (a) TiN/CrN, CrN, and TiN. (b) TiN/NbN, NbN, and TiN. (c) NbN/CrN, NbN, and CrN. (d) TiN, CrN, and NbN.

not be visible on the TEM micrographs, flattening of the rough coating surface, and dislocation-mediated plastic flow.

For the TiN/CrN [Fig. 9(d")] and NbN/CrN [Fig. 9(f')] coatings, indentation caused multilayer structural rotation similar to previous studies of polycrystalline ${ }^{39}$ and single-crystal coatings. ${ }^{67}$ Grain rotation is observed to be $\sim 10^{\circ}$ for $\mathrm{TiN} / \mathrm{CrN}$ and $\sim 15^{\circ}$ for $\mathrm{NbN} / \mathrm{CrN}$. Inclination of the TEM sample around the horizontal axis in plane with the layers confirmed that the multilayered structure was not destroyed by the plastic deformation and that there are not cracks in the multilayer coating that is contrary to other studies. ${ }^{9}$ Calculated deformation (Table I) is in the range of $\sim 16 \%$ for $\mathrm{NbN} / \mathrm{CrN}$ to $20 \%$ TiN/CrN of the initial coating thickness. The TiN/NbN combination [Fig. 9(b')] did not show a multilayer rotation as deformation is mainly accommodated by shearing perpendicular to the film.

A detailed analysis of the multilayer deformation in the center of the indentation can be seen in Fig. 10. For indentation into a flat, elastic half space, there is a gradient in the stress intensity beneath the indenter such that the maximum stress is at the depth of roughly $50 \%$ of the contact radius below the surface. Therefore, it is not surprising that deformation of the multilayers is not homogeneous as a function of depth. A good example of this is seen in Fig. 10(c) for the NbN/CrN coating where the highest deformation is seen from layers 28 to 36 (first deposited layer is marked in Fig. 10 as a number 1) with relative compression reaching $50 \%$ for those periods. This cross section does provide some insight as to why the $\mathrm{NbN} / \mathrm{CrN}$ film was characterized by sink-in for nanoscale indentations as seen with in situ movies. This could never be observed with any other method besides in situ SEM-indentation based technique since the final indent [Fig. 6(f)] shows a small amount of pileup. The plasticity of the $\mathrm{CrN}$ through most of the coating in Fig. 10(c) was confined by the stiffer $\mathrm{NbN}$ as a result of the crisp interfaces for these materials observed in Fig. 1. The flow in $\mathrm{CrN}$ and minimal deformation of $\mathrm{NbN}$ resulted in the formation of shear band extending for several layers [Fig. 9( $\left.f^{\prime}\right)$ ]. For example in Fig. 10(c), 


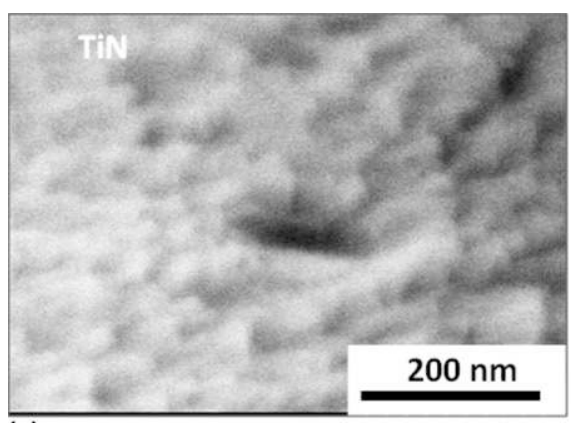

(a)

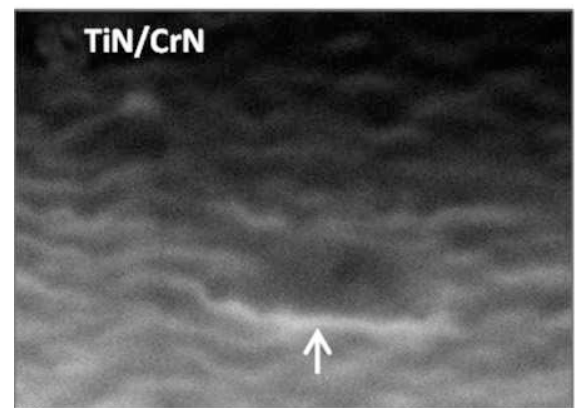

(d)

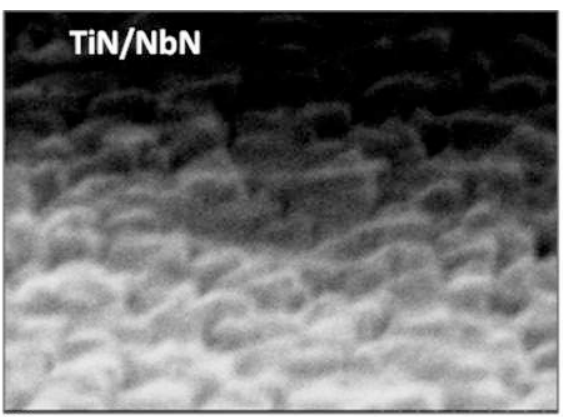

(b)

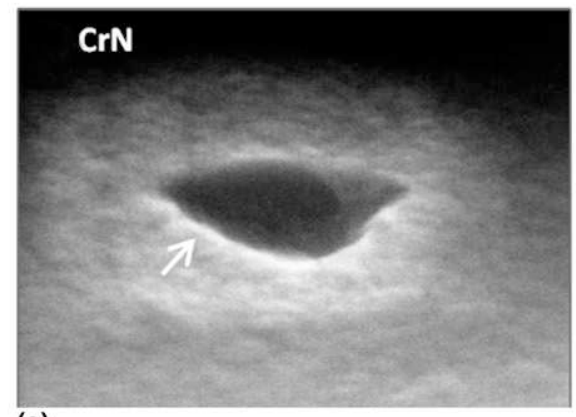

(e)

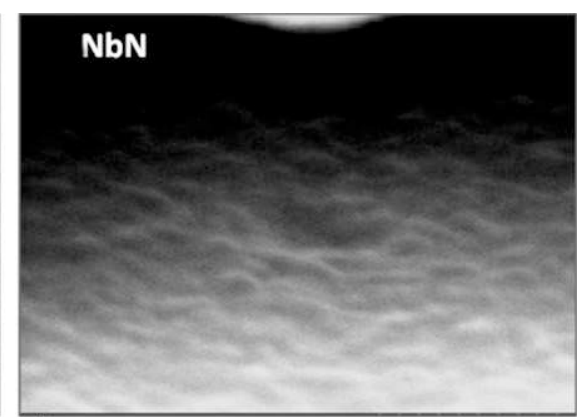

(c)

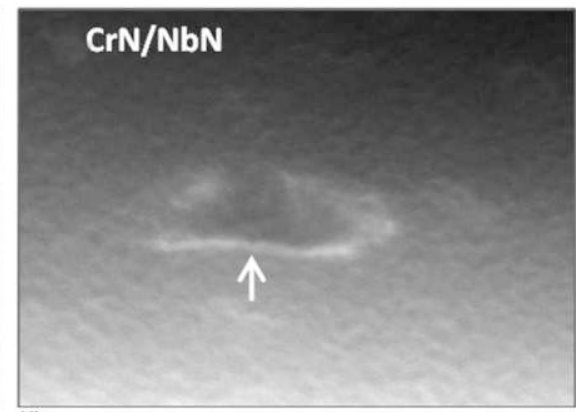

(f)

FIG. 6. In situ SEM nanoindentation images of the indentation imprints for a maximum load of $0.9 \mathrm{mN}$ on the following coatings: (a) TiN, (b) $\mathrm{TiN} / \mathrm{NbN}$, (c) $\mathrm{NbN}$, (d) TiN/CrN, (e) $\mathrm{CrN}$, and (f) $\mathrm{NbN} / \mathrm{CrN}$.

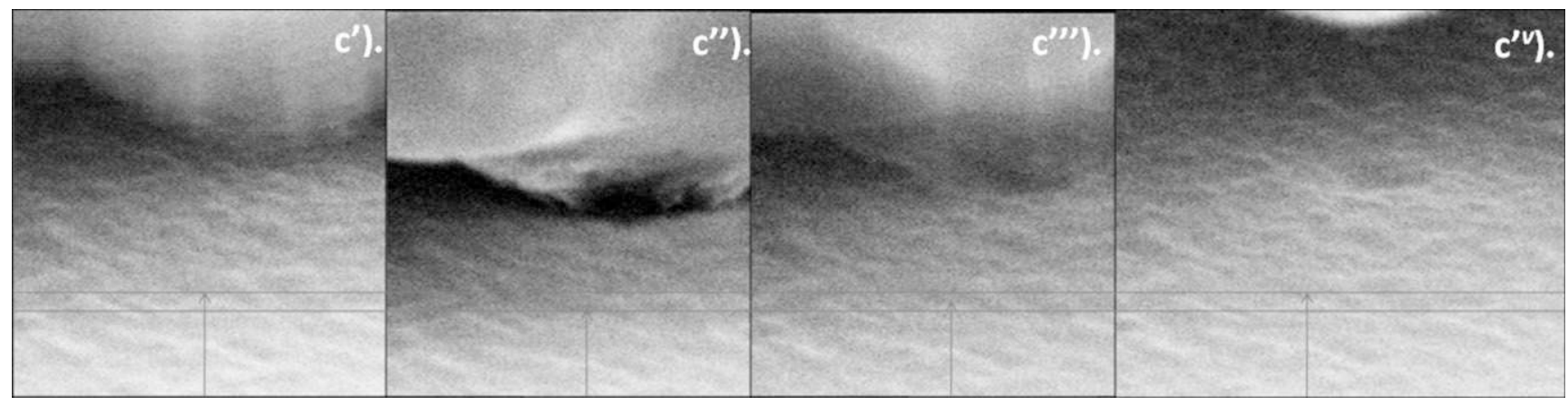

FIG. 7. Frames of the indentation from Fig. 6(c) showing sink-in of the NbN surface. $\left(c^{\prime}\right)$ Tip is approaching the sample surface. ( $\left.c^{\prime \prime}\right)$ Maximum load (maximum sink-in may be observed). ( $\left.c^{\prime \prime \prime}\right)$ Just after the tip retraction (sink-in did not recover fully yet). ( $\mathrm{c}^{\prime v}$ ) Postmortem SEM image with full recovering of the sink-in phenomena.

TABLE II. Cracking measured for coatings during in situ microindentation for a maximum load of $150 \mathrm{mN}$.

\begin{tabular}{lccc}
\hline \hline $\begin{array}{l}\text { Type of } \\
\text { coating }\end{array}$ & $\begin{array}{c}\text { Crack length for the } \\
\text { max. load }(\mu \mathrm{m})\end{array}$ & $\begin{array}{c}\text { Load for appearing } \\
\text { of crack }(\mathrm{mN})\end{array}$ & $\begin{array}{c}\text { Penetration } \\
\text { depth }(\mathrm{nm})\end{array}$ \\
\hline $\mathrm{TiN}$ & 5.11 & 57 & 932 \\
$\mathrm{CrN}$ & 10.1 & 147 & 1771 \\
$\mathrm{NbN}$ & $\ldots$ & $\ldots$ & $\ldots$ \\
$\mathrm{TiN} / \mathrm{NbN}$ & 9.8 & 73 & 1636 \\
$\mathrm{TiN} / \mathrm{CrN}$ & 11.4 & 71.8 & 1440 \\
$\mathrm{NbN} / \mathrm{CrN}$ & 3.8 & 133.4 & 652 \\
\hline \hline
\end{tabular}

the deformation of both constituent materials was approximately equal through layers 10 to 20 where stresses were lower than at layers 28 to 36 in this experiment. This similarity of deformation at larger indentation loads highlights the potential for nanolaminate strengthening at lower loads whereby a strong material and a tough material can combine their disparate properties into a single coating.

Uniformity of deformation is not seen in the other two multilayer combinations [Figs. 10(a) and 10(b)]. These materials possess rough interfaces and have grain orientations, which continue through multiple layers. For these films, strain localization was prevalent [Figs. 10(a) and 10(b)] and a rule-of-mixture with hardness (Table III) is found.

In the $\mathrm{TiN} / \mathrm{CrN}$ substrate for $30 \mathrm{mN}$ indentation, cracking in the substrate is generated during the loading part of the indentation experiment and can therefore be related to the pop-in in the load-displacement curve, as is discussed in Sec. III. D. Grain-boundary shearing for TiN is 

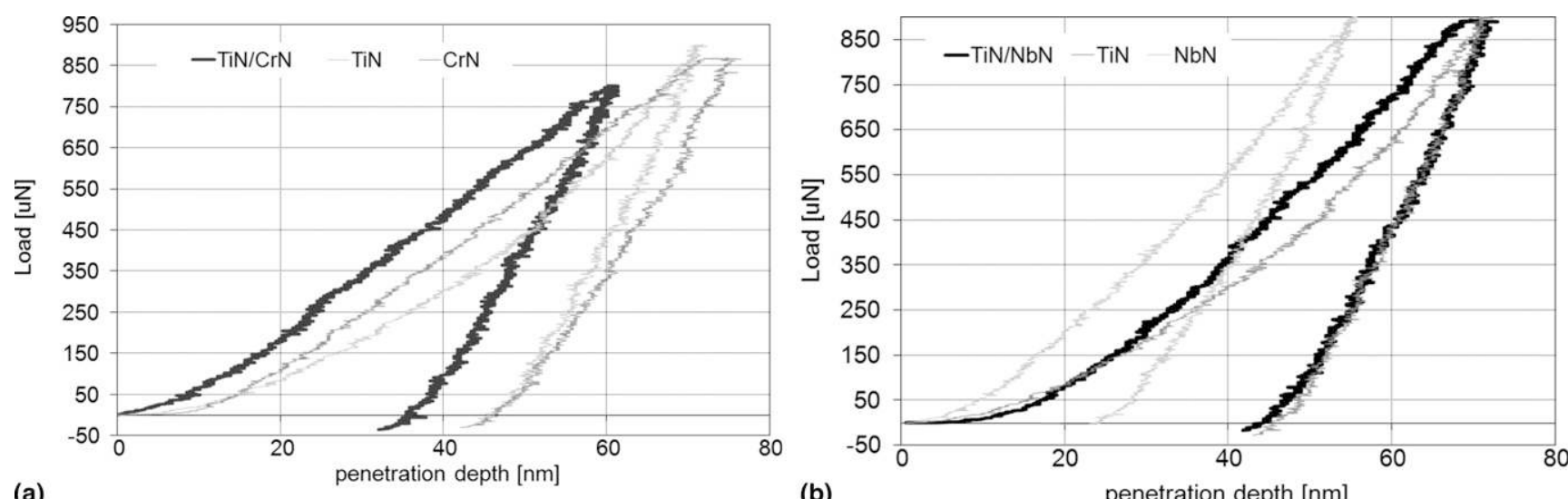

(a)

(b)
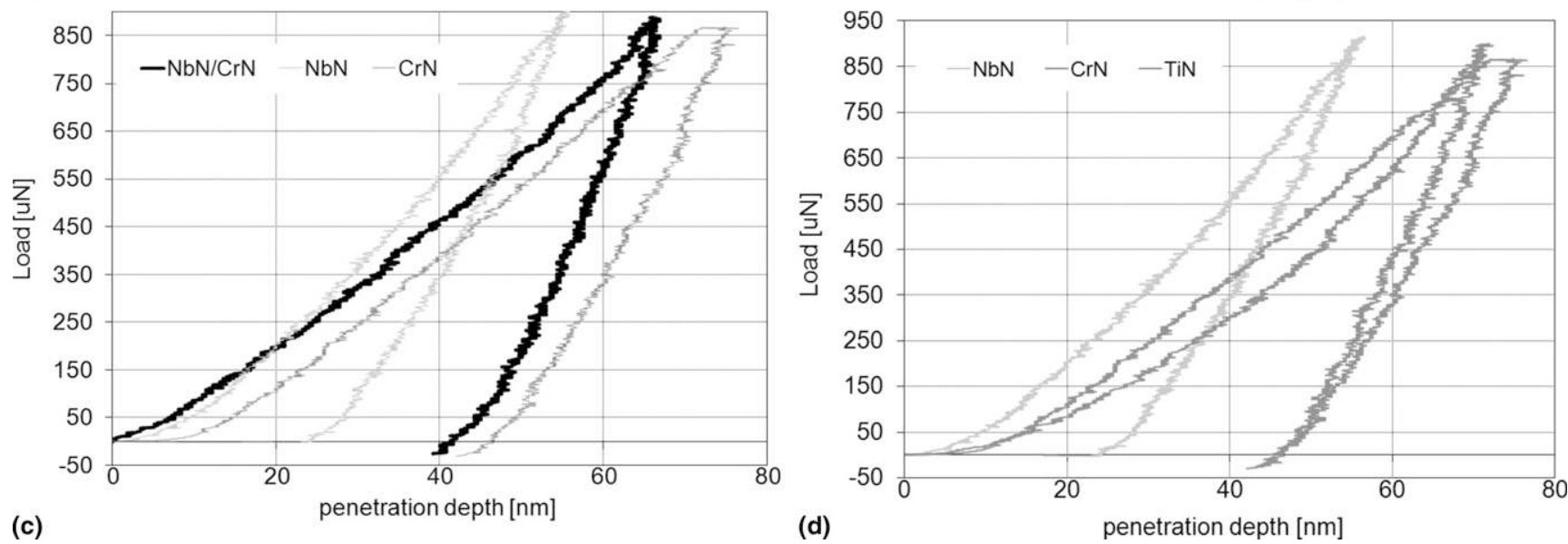

FIG. 8. Load-displacement curves recorded during in situ SEM nanoindentation presented in Fig. 6 for multilayers and corresponding reference coatings. (a) TiN/CrN, TiN and CrN. (b) TiN/NbN, TiN, and NbN. (c). NbN/CrN, NbN, and CrN. (d) TiN, CrN, and NbN. Surface roughness is evident as a lower slope at the initial stages (displacement $<20 \mathrm{~nm}$ ) of the load-displacement curve.

TABLE III. Hardness values obtained by the Hysitron TriboIndenter and PicoIndenter

\begin{tabular}{lcc}
\hline \hline $\begin{array}{c}\text { Type of } \\
\text { coating }\end{array}$ & $\begin{array}{c}\text { Hardness measured with } \\
\text { TriboIndenter (GPa) } \\
1000 \mu \mathrm{N}\end{array}$ & $\begin{array}{c}\text { Hardness calculated from the } \\
\text { in situ picoindentation (GPa) } \\
850 \mu \mathrm{N}\end{array}$ \\
\hline $\mathrm{TiN}$ & 15.00 & 10.54 \\
$\mathrm{CrN}$ & 16.59 & $\ldots$ \\
$\mathrm{NbN}$ & 26.46 & 37.84 \\
$\mathrm{TiN} / \mathrm{NbN}$ & 14.89 & 19.20 \\
$\mathrm{TiN} / \mathrm{CrN}$ & 14.67 & 10.48 \\
$\mathrm{NbN} / \mathrm{CrN}$ & 18.63 & 37.75 \\
\hline \hline
\end{tabular}

visible through shear steps at the substrate interface [Fig. 9(d'), arrow]. The TiN/NbN multilayer coating presents the most developed damage of the substrate where radial cracking is accompanied by symmetrical lateral cracks. Here, as seen in Fig. 9(b), the TiN sublayers deform to a larger extent than the $\mathrm{NbN}$, which results in the through-thickness shearing of the $\mathrm{NbN}$ sublayers [Fig. 9(b $\left.\left.b^{\prime}\right)\right]$. Moreover, across the entire thickness of the multilayer coating, TiN layers exhibit a larger compression than NbN sublayers [Fig. 10(b)].

\section{F. Overall deformation and fracture behavior}

The combination of different measurement techniques, including in situ SEM micro- and nanoindentation, and cross-sectional TEM of the resulting deformation verified that the correlation of the appearance of cracks and discontinuities on the load-displacement curve is not always straightforward. In situ indentation has shown that many times cracks appear without a corresponding displacement burst. In fact, the cracking of the coatings is preceded by substrate cracking at lower loads for these coating/substrate combinations. All of the coatings, except $\mathrm{NbN}$, show radial cracks having their source in the lateral substrate cracking. Even though the $\mathrm{NbN}$ did not crack, it did spall thus exposing the fracture that had occurred in the substrate as seen in the SEM micrograph of $\mathrm{NbN}$ [Fig. 3(c)]. The $\mathrm{CrN}$ reference coating plastically deforms starting with pileup, which develops into shear bands while the TiN deforms via grain-boundary sliding and cracking along the grain boundaries in addition to slight piling up and finally cracks.

The deformation mechanisms of the multilayers are characterized by the mechanisms of the constituent layers; however, they combine differently. For example, 


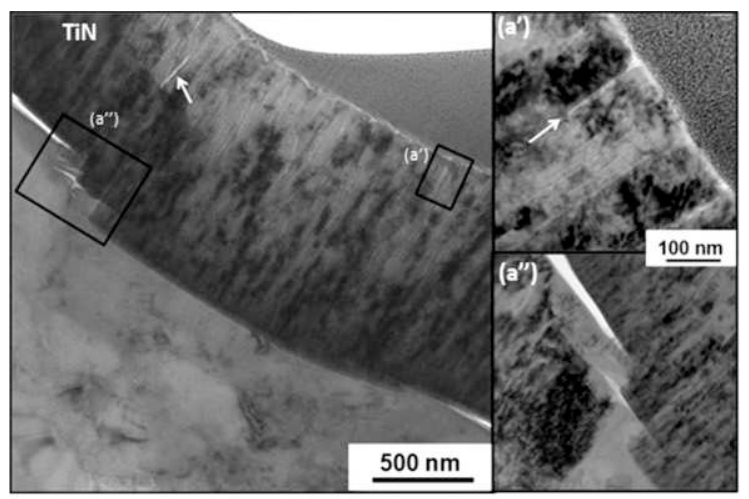

(a)

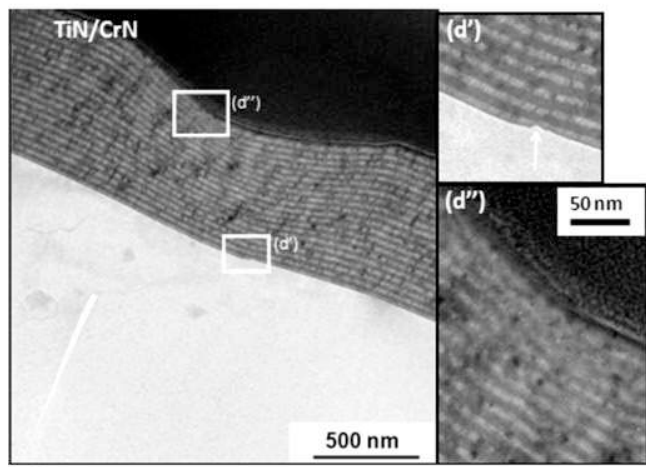

(d)

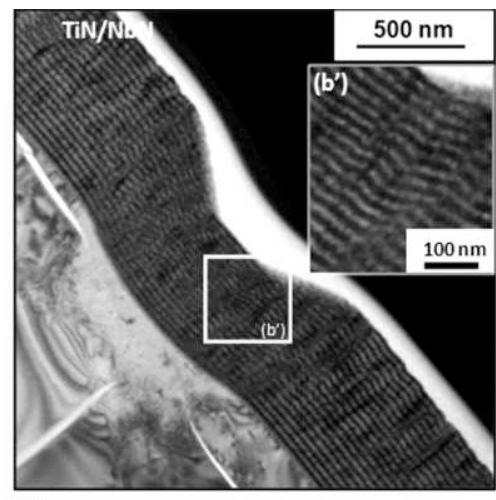

(b)

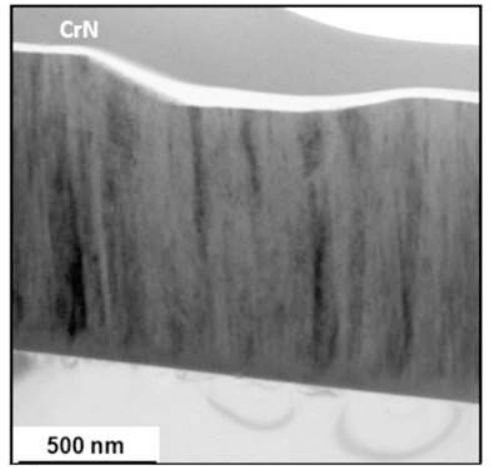

(e)

(f)

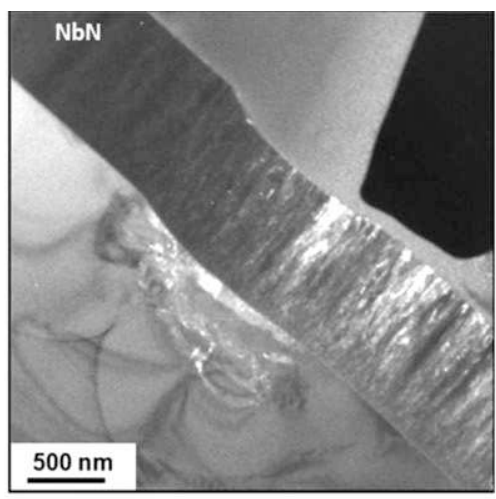

(c)

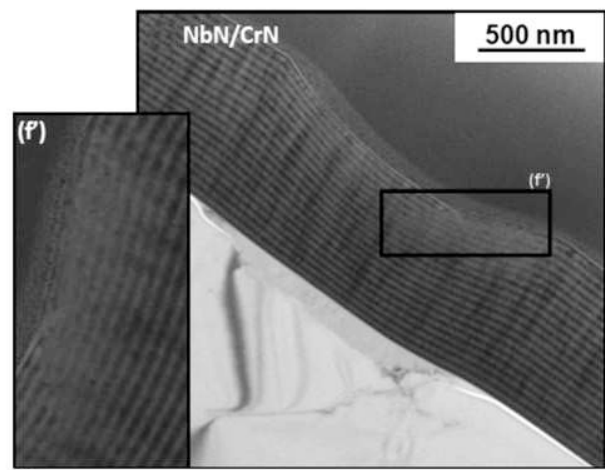

FIG. 9. TEM cross sections through indents ( $30 \mathrm{mN}$ maximum load) performed on the coatings (a) TiN. ( $\left.\mathrm{a}^{\prime}\right)$ Intergranular cracks. ( $\left.\mathrm{a}^{\prime \prime}\right)$ Shear steps at the surface/coating interface. (b) TiN/NbN. (b') Showing grain-boundary sliding within TiN layers. (c) NbN. (d) TiN/CrN. (d') Shear step caused by the TiN grain-boundary shearing at the coating/substrate interface. $\left(\mathrm{d}^{\prime \prime}\right)$ Layer rotation in the indentation imprint visible as a loss of sharpness. (e) $\mathrm{CrN}$. (f) $\mathrm{NbN} / \mathrm{CrN}$. (f') Showing shearing beneath the indentation imprint and layer rotation.

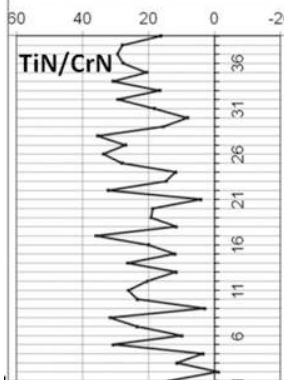

(a)

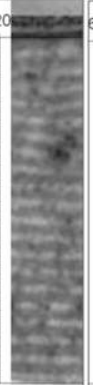

(b)

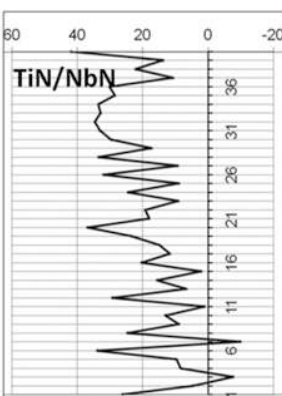

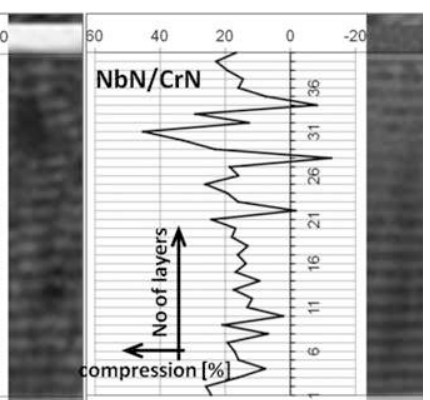

(c)

FIG. 10. Detailed analysis of the compression of the layers in the multilayer coatings through the thickness underneath the center of the $30 \mathrm{mN}$ indents from Fig. 9 for: (a) TiN/CrN, (b) TiN/NbN, and (c) NbN/CrN.

grain-boundary sliding, which is characteristic for TiN, is much more apparent in the TiN/NbN combination, where $\mathrm{NbN}$ acts like a rigid plate, than for the $\mathrm{TiN} / \mathrm{CrN}$, where deformation is taken over by both constituent layers. Additionally, multilayers that contain $\mathrm{NbN}$ show improvement in adhesion compared with the $\mathrm{NbN}$ reference coating, and the pileup tendency of $\mathrm{CrN}$ is mitigated in the multilayer combinations. Qualitatively, larger deformation, longer cracks, and more pronounced fracture of the substrates underneath the indentation imprints was observed for the multilayers compared with the reference coatings.
At the nanoscale, each of the coatings exhibited specific mechanisms such as sink-in for $\mathrm{NbN}$ and $\mathrm{NbN} / \mathrm{CrN}$ multilayers and varying degrees of pileup observed after unloading for $\mathrm{CrN}$, TiN, TiN/CrN, and $\mathrm{TiN} / \mathrm{NbN}$. It should be noted that while the NbN/CrN coating shows minimal pileup after indentation, both it and the other coatings containing $\mathrm{NbN}$ exhibited sink-in behavior during indentation. Therefore, all coatings with $\mathrm{NbN}$ show an increase in hardness when calculating hardness from the in situ SEM images. The high nanohardness value (Table III) and smaller amount of compression (Table I) of the $\mathrm{NbN} / \mathrm{CrN}$ combination relative to the 
TiN/NbN coating was probably caused by the sharp and smooth interfaces that confine $\mathrm{CrN}$ plasticity. This is interesting since the TiN reference film deforms much less than the $\mathrm{CrN}$ reference film, and it shows that interfaces can play a significant role in overall deformation.

\section{CONCLUSIONS}

Deformation and fracture mechanisms of the multilayer transition metal nitride coatings, $\mathrm{TiN} / \mathrm{CrN}, \mathrm{TiN} / \mathrm{NbN}$ and $\mathrm{NbN} / \mathrm{CrN}$ and corresponding reference coatings of $\mathrm{TiN}$, $\mathrm{NbN}$ and $\mathrm{CrN}$ were systematically investigated using a combination of in situ micro- and nanoindentation and postmortem analysis of the indents by transmission electron microscopy. In situ SEM microindentation allowed for observation of fracture events, pileup, and sink-in of the coating/substrate system during indentation and demonstrated that fracture events do not always show up as discontinuities in the load-displacement curve. In situ SEM nanoindentation enabled the coating to be mechanically probed and roughness, pileup, and sink-in to be taken into account. In particular, the contact area calculated directly from the SEM image taken while the tip was under maximum load was shown to differ significantly from the one calculated using a standard Oliver and Pharr approach because of the factors mentioned previously. Postmortem TEM analysis of the deformed areas was used to assess the mechanisms of deformation of the coatings, and in particular an analysis of the compression ratio of the sublayers in the multilayers gave insight into the deformation mechanics at this scale.

Within measurement accuracy, the multilayer coatings exhibited no increase in hardness or reduced modulus when compared with the reference coatings. The deformation mechanisms of the multilayers are characterized by the mechanisms of the constituent layers; however, they do combine differently. Grain-boundary sliding, which is mechanism characteristic for $\mathrm{TiN}$, is much more apparent in the $\mathrm{TiN} / \mathrm{NbN}$ combination than in TiN/CrN. This is probably due to NbN-rigid-plate behavior in $\mathrm{TiN} / \mathrm{NbN}$, while in $\mathrm{TiN} / \mathrm{CrN}$ the deformation is taken over by both constituent layers. Both multilayer coatings containing $\mathrm{NbN}$ exhibited sink-in during indentation; however, the $\mathrm{NbN} / \mathrm{CrN}$ coating deforms less than the TiN/NbN combination, even though the reference films of $\mathrm{CrN}$ and $\mathrm{TiN}$ show the opposite behavior (Table I). It is thought that this is caused by the smooth interfaces that form in the $\mathrm{NbN} / \mathrm{CrN}$ coating, compared with the TiN/NbN interfaces, such that the $\mathrm{NbN}$ is able to confine the $\mathrm{CrN}$ deformation. This example illustrates the importance of the state of the interface to the overall mechanical behavior of the coating and shows that the enhancement of constituent materials within a multilayer coating is possible.

\section{ACKNOWLEDGMENTS}

The authors would like to acknowledge S. Meier and J. Tharian, EMPA Duebendorf, for FIB samples preparation. We are grateful to Prof. R. Spolenak and M. Dietiker (ETH Zürich) for making the TriboIndenter accessible to our use and help in experiments. We thank Prof. W. Clegg and S. Corte (University of Cambridge) for helpful discussions. I also want to express special thanks to our colleagues form EMPA Thun, P. Schwaller, A. Bidiville, and F. Oestlund for fruitful discussions, M. Aeberhard for GDOES measurements, and G. Bürki for overall technical support. Finally, we acknowledge financial support from the European Commission in the framework of the project M3-2S under Contract No. 206486/1127.074.

\section{REFERENCES}

1. P.H. Mayrhofer, Ch. Mitterer, and L. Hultman: Microstructural design of hard coatings. Prog. Mater. Sci. 51, 1032 (2006).

2. S.C. Tjong and H. Chen: Nanocrystalline materials and coatings. Mater. Sci. Eng. 45, 1 (2004).

3. W.D. Sproul: New routes in preparation of mechanically hard films. Science 273, 889 (1996).

4. I. Petrov, L. Hultman, U. Helmersson, J.E. Sundgren, and J.E. Green: Microstructure modification of TiN by ion bombardment during reactive sputter deposition. Thin Solid Films 169, 299 (1989).

5. W.D. Sproul, P.J. Rudnik, and M.E. Graham: The effect of $\mathrm{N}_{2}$ partial pressure, deposition rate and substrate bias potential on the hardness and texture of reactively sputtered TiN coatings. Surf. Coat. Technol. 39-40, 355 (1989).

6. D.F. Arias, Y.C. Arango, and A. Devia: Study of TiN and $\mathrm{ZrN}$ thin films grown by cathodic arc technique. Appl. Surf. Sci. 253, 1683 (2006).

7. Q. Yang, D.Y. Seo, and L.R. Zhao: Multilayered coatings with alternate pure Ti and TiNyCrN superlattice. Surf. Coat. Technol. 177-178, 204 (2004).

8. B. Mirkarimi, S.A. Barnett, K.M. Hubbard, T.R. Jervis, and L. Hultman: Structure and mechanical properties of epitaxial $\mathrm{TiN} / \mathrm{V}_{0.3} \mathrm{Nb}_{0.7} \mathrm{~N}$ (100) superlattices. J. Mater. Res. 9, 1456 (1994).

9. C. Mendibide, J. Fontaine, P. Steyer, and C. Esnouf: Dry sliding wear model of nanometer scale multilayered TiN/CrN PVD hard coatings. Tribol. Lett. 17, 779 (2004).

10. W.H. Zhang and J.H. Hsieh: Tribological behavior of TiN and CrN coatings sliding against an epoxy molding compound. Surf. Coat. Technol. 130, 240 (2000).

11. M. Oden, C. Ericsson, G. Hakansson, and H. Ljungcrantz: Microstructure and mechanical behavior of arc-evaporated $\mathrm{Cr}-\mathrm{N}$ coatings. Surf. Coat. Technol. 114, 39 (1999).

12. G.A. Fontalvo, V. Terziyska, and C. Mitterer: High-temperature tribological behaviour of sputtered $\mathrm{NbN}_{\mathrm{x}}$ thin films. Surf. Coat. Technol. 202, 1017 (2002).

13. C.S. Sandu, M. Benkahoul, M. Parlinska-Wojtan, R. Sanjinés, and R. Lévy: Morphological, structural and mechanical properties of $\mathrm{NbN}$ thin films deposited by reactive magnetron sputtering. Surf. Coat. Technol. 200, 6544 (2006).

14. Z. Han, X. Hu, J. Tian, G. Li, and G. Mingyuan: Magnetron sputtered $\mathrm{NbN}$ thin films and mechanical properties. Surf. Coat. Technol. 179, 188 (2004).

15. Y.L. Su and J.S. Lin: An investigation of the tribological potential of TiN, CrN and $\mathrm{TiN}+\mathrm{CrN}$ physical vapor deposited coatings in machine element applications. Wear 170, 45 (1993). 
16. Z.G. Zhang, O. Rapaud, N. Bonasso, D. Mercs, C. Dong, and C. Coddet: Control of microstructures and properties of dc magnetron sputtering deposited chromium nitride films. Vacuum $\mathbf{8 2}$, 501 (2008)

17. I. Milosev, J.M. Abels, H-H. Strehblow, B. Naviasek, and M. Metikos-Hukovic: High temperature oxidation of thin $\mathrm{CrN}$ coatings deposited on steel. J. Vac. Sci. Technol. A 14, 2527 (1996).

18. T. Hurkmans, D.B. Lewis, J.S. Brooks, and W-D. Munz: Chromium nitride coatings grown by unbalanced magnetron (UBM) and combined arc/unbalanced magnetron (ABS TM) deposition techniques. Surf. Coat. Technol. 86, 192 (1996).

19. R. Hubler, A. Cozza, T.L. Marcondes, R.B. Souza, and F.F. Fiori: Wear and corrosion protection of 316-L femoral implants by deposition of thin films. Surf. Coat. Technol. 142, 1078 (2001).

20. P. Panjan, B. Navinsek, A. Cvelbar, A. Zalar, and I. Milosev: Oxidation of TiN, ZrN, TiZrN, CrN, TiCrN, and TiN/CrN multilayer hard coatings reactively sputtered as a low temperature. Thin Solid Films 281, 298 (1996).

21. S. Kanamori: Investigation of reactively sputtered TiN films for diffusion barriers. Thin Solid Films 136, 195 (1986).

22. K. Hinode, Y. Homma, M. Horiuchi, and T. Takahashi: Morphology-dependent oxidation behavior of reactively sputtered titanium-nitride films. J. Vac. Sci. Technol. A 15, 2017 (1997).

23. M.J. Deen: Effect of the deposition rate on the properties of d.c.magnetron-sputtered niobium nitride thin films. Thin Solid Films 152, 535 (1987).

24. D.F. Dawson-Elli, F. David, C.A. Fung, and J.E. Nordman: DC reactive magnetron sputtered $\mathrm{NbN}$ thin films prepared with and without hollow cathode enhancement. IEEE Trans. Magn. 27, 1592 (1991).

25. I.L. Singer, R.N. Bolster, S.A. Wolf, E.F. Skelton, and R.A. Jeffries: Abrasion resistance, microhardness and microstructures of single-phase niobium nitride films. Thin Solid Films 107, 207 (1983).

26. Y. Gotoh, M. Nagao, T. Ura, H. Tsuji, and J. Ishikawa: Ion-beamassisted deposition of niobium nitride thin films for vacuum microelectronic devices. Nucl. Instrum. Methods Phys. Res. B 148, 925 (1999).

27. K.S. Havey, J.S. Zabinski, and S.D. Walck: The chemistry, structure, and resulting wear properties of magnetron-sputtered $\mathrm{NbN}$ thin films. Thin Solid Films 303, 238 (1997).

28. A. Mumtaz and W.H. Class: Color of titanium nitride prepared by reactive dc magnetron sputtering. J. Vac. Sci. Technol. 20, 345 (1981).

29. B.J. Daniels, W.D. Nix, and B.M. Clemens: Enhanced mechanical hardness in compositionally modulated $\mathrm{Fe}(001) / \mathrm{Pt}(001)$ and $\mathrm{Fe}(001) / \mathrm{Cr}(001)$ epitaxial thin films. Thin Solid Films 253, 218 (1994).

30. M. Nordin, M. Larsson, and S. Hogmark: Mechanical and tribological properties of multilayered PVD TiN/CrN,TiN/MoN, TiN/ $\mathrm{NbN}$ and TiN/TaN coatings on cemented carbide. Surf. Coat. Technol. 106, 234 (1998).

31. J.M. Molina-Aldareguia, S.J. Lloyd, S.J. Oden, T. Joelsson, L. Hultman, and W.J. Clegg: Deformation structures under indentations in $\mathrm{TiN} / \mathrm{NbN}$ single-crystal multilayers deposited by magnetron sputtering at different bombarding ion energies. Philos. Mag. A 82, 1983 (2002).

32. S.Y. Lee, G.S. Kim, and J.H. Hahn: Effect of the Cr content on the mechanical properties of nanostructured TiN/CrN coatings. Surf. Coat. Technol. 177, 426 (2004).

33. H.C. Barshilia and K.S. Rajam: Structure and properties of reactive DC magnetron sputtered TiN/NbN hard superlattices. Surf. Coat. Technol. 183, 174 (2004).
34. B.C. Kang, H.Y. Kim, O.Y. Kwon, and S.H. Hong: Bilayer thickness effects on nanoindentation behavior of $\mathrm{Ag} / \mathrm{Ni}$ multilayers. Scr. Mater. 57, 703 (2007).

35. M. Verdier, H. Huang, F. Spaepen, J.D. Embury, and H. Kung: Microstructure, indentation and work hardening of $\mathrm{Cu} / \mathrm{Ag}$ multilayers. Philos. Mag. 86, 5009 (2006).

36. Y-M. Luo, W. Pan, S.Q. Li, J. Chen, R.G. Wang, and J.Q. Li: Mechanical properties and microstructure of a $\mathrm{Si}_{3} \mathrm{~N}_{4} / \mathrm{Ti}_{3} \mathrm{SiC}_{2}$ multilayer composite. Ceram. Int. 28, 223 (2002).

37. V.I. Vdovin: Misfit dislocations in epitaxial heterostructures: Mechanisms of generation and multiplication. Phys. Status Solidi A 171, 239 (1999)

38. J. Ding, Y. Meng, and S. Wen: Mechanical properties and fracture toughness of multilayer hard coatings using nanoindentation. Thin Solid Films 371, 178 (2000).

39. N.J.M. Carvalho and J.Th.M. De Hosson: Deformation mechanisms in TiN/(Ti,Al)N multilayers under depth-sensing indentation. Acta Mater. 54, 1857 (2006).

40. X. Chu and S.A. Barnett: Model of superlattice yield stress and hardness enhancements. J. Appl. Phys. 77, 4403 (1994).

41. Y. Long, F. Giuliani, S.J. Lloyd, J. Molina-Aldareguia, Z.H. Barber, and W.J. Clegg: Deformation processes and the effects of microstructure in multilayered ceramics. Composites: Part B 37, 542 (2006).

42. J. Musil, F. Kunc, H. Zeman, and H. Polakova: Relationships between hardness, Young's modulus and elastic recovery in hard nanocomposite coatings. Surf. Coat. Technol. 154, 304 (2002).

43. H. Wrzesinska, P. Grabiec, Z. Rymuza, and M. Misiak: Influence of substrate on mechanical properties of $\mathrm{TiN} / \mathrm{NbN}$ superlattices. Microelectron. Eng. 61, 1009 (2002).

44. Y.L. Su and S.H. Yao: On the performance and application of CrN coating. Wear 205, 112 (1997).

45. M. Okumiya and M. Griepentrog: Mechanical properties and tribological behavior of TiN-CrAlN and $\mathrm{CrN}-\mathrm{CrAlN}$ multilayer coatings. Surf. Coat. Technol. 112, 123 (1999).

46. O. Borrero-Lopez, M. Hoffman, A. Bendavid, and P.J. Martin: A simple nanoindentation-based methodology to assess the strength of brittle thin films. Acta Mater. 56, 1633 (2008).

47. B. Moser, J.F. Löffler, and J. Michler: Discrete deformation in amorphous metals: An in situ SEM indentation study. Philos. Mag. 86, 5715 (2006).

48. R. Rabe, J-M. Breguet, P. Schwaller, S. Stauss, F-J. Haug, J. Patscheider, and J. Michler: Observation of fracture and plastic deformation during indentation and scratching inside the scanning electron microscope. Thin Solid Films 469, 206 (2004).

49. K.A. Rzepiejewska-Malyska, M. Parlinska-Wojtan, K. Wasmer, K. Hejduk, and J. Michler: In situ SEM indentation studies of the deformation mechanisms in $\mathrm{TiN}, \mathrm{CrN}$ and TiN/CrN. Micron. 40, 22 (2009).

50. H. Wrzesinska, J. Ratajczak, K. Studzinska, and J. Katcki: Transmission electron microscopy of hard ceramic superlattices applied in silicon micro-electro-mechanical systems. Mater. Chem. Phys. 81, 265 (2003).

51. Y. Zhou, R. Asaki, W-H. Soe, R. Yamamoto, and R. Chen: Hardness anomaly, plastic deformation work and fretting wear properties of polycrystalline TiN/CrN multilayers. Wear 236, 159 (1999).

52. J.R. Tuck, A.M. Korsunsky, D.G. Bhat, and S.J. Bull: Indentation hardness evaluation of cathodic arc deposited thin hard coatings. Surf. Coat. Technol. 139, 63 (2001).

53. S. Veprek: The search for novel, superhard materials. J. Vac. Sci Technol. A 17, 2401 (1999). 
54. H. Hollek: Binary and Ternary Carbide and Nitride Systems of Transition Metals (Gebrüder Borntraeger, Berlin, 1984).

55. K.A. Rzepiejewska-Malyska, R.C. Major, G. Buerki, E. Cyrankowski, S. Asif, O. Warren, and J. Michler: In situ mechanical observations during nanoindentation inside a high resolution scanning electron microscope. J. Mater. Res. 23, 1973 (2008).

56. B. Naviasek, P. Panjan, and A. Cvelbar: Characterization of low temperature $\mathrm{CrN}$ and TiN (PVD) hard coatings. Surf. Coat. Technol. 74, 155 (1995).

57. F. Hollstein, R. Wiedemann, and J. Scholz: Characteristics of PVD-coatings on AZ31hp magnesium alloys. Surf. Coat. Technol. 162, 261 (2003).

58. W. Krysicki, J. Bartos, W. Dyczka, K. Królikowska, and M. Wasilewski: The Theory of Probability and Mathematical Statistics in Exercises. Mathematical Statistics, Part 2 (Wydawnictwo Naukowe PWN, 2006).

59. V. Poulek, J. Musil, R. Cerny, and R. Kuzel: $\varepsilon-\mathrm{Ti}_{2} \mathrm{~N}$ phase growth control in titanium nitride films. Thin Solid Films 170, L55 (1989).

60. P.R. LeClair: Titanium nitride thin films by the electron shower process. Ph.D. Thesis. Massachusetts Institute of Technology, Boston, MA (1998).
61. Yu.V. Levinskiy: Phase diagrams of metals with gases. Russ. Metall. 34, (1974).

62. W. Lengauer, M. Bohn, B. Wollein, and K. Lisak: Phase reactions in the Nb-N system below 1400 C. Acta Mater. 48, 2633 (2000).

63. M. Oden, U.J. Almer, G. Hakansson, and M. Olsson: Microstructure property relationships in arc-evaporated $\mathrm{Cr}-\mathrm{N}$ coatings. Thin Solid Films 377, 407 (2000).

64. C. Rebholz, H. Ziegele, A. Leyland, and A. Matthews: Structure, mechanical and tribological properties of nitrogen-containing chromium coatings prepared by reactive magnetron sputtering. Surf. Coat. Technol. 115, 222 (1999).

65. W.C. Oliver and G.M. Pharr: An improved technique for determining hardness and elastic modulus using load and displacement sensing indentation experiments. J. Mater. Res. 7, 1564 (1992).

66. S.J. Bull: Using work of indentation to predict erosion behavior in bulk materials and coatings. J. Phys. D: Appl. Phys. 39, 1626 (2006).

67. A.M. Minor, E.A. Stach, J.W. Morris, and I. Petrov: In situ nanoindentation of epitaxial $\mathrm{TiN} / \mathrm{MgO}(001)$ in a transmission electron microscope. J. Electron. Mater. 32, 1023 (2003). 